\title{
Éric Tourrette, Les formes brèves de la description morale. Quatrains, maximes, remarques
}

\section{Michele Mastroianni}

\section{(2) OpenEdition}

1 Journals

\section{Edizione digitale}

URL: http://journals.openedition.org/studifrancesi/7892

DOI: $10.4000 /$ studifrancesi.7892

ISSN: 2421-5856

\section{Editore}

Rosenberg \& Sellier

\section{Edizione cartacea}

Data di pubblicazione: 1 juillet 2009

Paginazione: 385

ISSN: 0039-2944

\section{Notizia bibliografica digitale}

Michele Mastroianni, «Éric Tourrette, Les formes brèves de la description morale. Quatrains, maximes, remarques», Studi Francesi [Online], 158 (LIII | II) | 2009, online dal 30 novembre 2015, consultato il 09 janvier 2021. URL: http://journals.openedition.org/studifrancesi/7892 ; DOI: https://doi.org/10.4000/ studifrancesi.7892

Questo documento è stato generato automaticamente il 9 janvier 2021.

\section{(c) (1)}

Studi Francesi è distribuita con Licenza Creative Commons Attribuzione - Non commerciale - Non opere derivate 4.0 Internazionale. 


\title{
Éric Tourrette, Les formes brèves de la description morale. Quatrains, maximes, remarques
}

\author{
Michele Mastroianni
}

\section{NOTIZIA}

ÉRIC TOURRETTE, Les formes brèves de la description morale. Quatrains, maximes, remarques, Paris, Champion, 2008 («Moralia», 14), pp. 520.

1 A pochi anni di distanza dall'importante studio di Stefano Genetti (Saperla corta. Forme brevi sentenziose e letteratura francese, Fasano, Schena, 2002), la thèse di dottorato di Éric Tourrette studia l'evolversi in Francia del genere letterario della forma breve, dall'ultimo quarto del Cinquecento a tutto il Seicento, scandendo quest'evoluzione in particolare sui seguenti autori: Guy Pibrac, Antoine Favre, Claude Guichard, Pierre Mathieu, Guillaume Colletet, Nicolas d'Ailly, la marchesa de Sablé, La Rochefoucauld, La Bruyère, il Théophraste moderne, Morvan de Bellegarde. I termini dell'inchiesta sono il 1574 (prima edizione dei Quatrains di Pibrac) e il 1701 (seconda edizione del Théophraste moderne). Partendo dalla distinzione tra style ed écriture, sfruttando soprattutto a livello metodologico alcuni suggerimenti di R. Barthes, l'A. si propone di giungere all'identificazione e descrizione di un'écriture moraliste. Per fare questo cerca di descrivere tre scritture distinte (anche se tra queste tre scritture riconosce orientamenti trasversali e una rete globale di riferimenti): si tratta di tre generi di forma breve, e precisamente del quatrain morale (alla maniera di Pibrac), della maxime mondana (alla maniera di La Rochefoucauld) e della remarque (alla maniera di La Bruyère). L'indagine di É. Tourrette non si propone di costruire una storia letteraria degli autori studiati, ma piuttosto di definire i suddetti tre generi, di cui vengono evidenziate, in un'analisi minuziosa, le caratteristiche retoriche. Viene inoltre designato quello che Tourrette, adattando una formula di L. Spitzer, definisce l'étymon générique «che, solo, può dare una piena coerenza formale al vasto corpus dei moralisti, 
e permette di raggruppare, di gerarchizzare, di integrare la maggior parte dei dettagli stilistici messi in evidenza dalle analisi puntuali»: si tratta di quel discernement di cui parlano anche i moralisti in questione, discernement inteso "come triplice tecnica di visione, di selezione e di distinzione». Sempre secondo Tourrette, ne consegue «un metodo, spesso associato alle immagini del rigore scientifico, delle misure oggettive, che è ad un tempo un'arte del pensare e un'arte dello scrivere, un atteggiamento filosofico e una dominante stilistica, in quanto il moralista aspira a vedere i referenti con la più grande nettezza, a opporli finemente gli uni agli altri e a stabilire fra di loro scelte motivate con precisione». 